\title{
New class of reactive novolac: synthesis of bisphenol A-based novolac with methylol groups
}

\author{
Tadamasa Nemoto and Gen-ichi Konishi
}

Polymer Journal (2010) 42, 185-189; doi:10.1038/pj.2009.319; published online 23 December 2009

Keywords: addition-condensation; bisphenol A; cure; methylol group; novolac; reactive polymer; thermal property

\begin{abstract}
'Novolacs' are the first synthetic resins to be prepared by acidcatalyzed addition-condensation of phenol with formaldehyde ${ }^{1}$ and have already been used in practical application. These resins have interesting properties that make them suitable for industrial use, such as thermostability and mechanical strength. ${ }^{2-17}$ During the curing of novolacs, hexamethylenetetramine (HMTA) is frequently used as the curing agent; ${ }^{1}$ however, the resultant curing products usually tend to contain amine derivatives and the unreacted curing agent as impurities, which often lead to coloration and degradation of the products.

Phenolic resins, called 'resol' resins, are prepared by base-catalyzed addition-condensation. ${ }^{1}$ As compared with novolacs, the resol resins have a number of methylol groups, which are introduced by the addition reaction of formaldehyde and phenol, and these groups react with electron-rich aromatic rings in the presence of heat or acids; consequently, resol resins are called thermosetting or reactive resins. ${ }^{18-21}$ Resol resins are suitable for use as polymer additives, crosslinking agents and so on However, the architecture of their main chains is such that it contains both $\mathrm{Ph}-\mathrm{CH}_{2}-\mathrm{Ph}$ and $\mathrm{Ph}-\mathrm{CH}_{2}-\mathrm{O}-$ $\mathrm{CH}_{2}-\mathrm{Ph}$ units. ${ }^{18}$ The latter unit is responsible for the deterioration of the product, which is characteristic of phenolic resins; the properties that deteriorate include thermal stability and mechanical property. Therefore, it is desirable to prepare the phenolic resins with methylol moieties by acid-catalyzed addition-condensation reaction, such that the structure of the main chains of resols is identical to those of novolacs; this reaction may afford other functional polymers exhibiting same properties as resol resins.
\end{abstract}

Among functional polymers, reactive polymers have been attracting the attention of researchers, particularly material scientists. ${ }^{22-30}$ Reactive polymers can be expected to exhibit additional properties by undergoing modification to produce many other polymers by polymer reactions; in addition to this, they are also expected to be used as cross-linking reagents, resist materials and so on. We have already reported the use of formyl or acetyl group-containing novolacs as reactive phenolic resins. ${ }^{31,32}$ These novolacs showed excellent abilities to form reversible gels with diamine and to undergo polymer reactions with Grignard reagents; therefore, these novolacs can be considered as reactive polymers.

In order to develop a novel phenolic resin, we attempted to use the methylol moiety on the benzene ring, which is formed as an intermediate during the acid-catalyzed addition-condensation reaction between phenol or phenol derivatives and formaldehyde. Imoto and others $^{33}$ reported on the methylol groups that were protected with propionic acid used as a solvent formed during the acid-catalyzed addition-condensation of diphenyl ether with formaldehyde, and that inhibited the formation of high-molecular-weight novolacs (molecular weight: $\approx 1500$ ). They did not make further reference to this formation; however, we focused on this protected methylol groups because the resulting product with protected methylol groups would show better stability, and it can serve as a reactive polymer (curing agent) such as resol resins on treatment with a base. Furthermore, by using alkoxylated phenol derivatives as the substrate, we can obtain desired products having methylol groups, which would not exhibit re-hardening, as in the case of resol resins because of a lower reactivity. In this study, we synthesized a bisphenol A novolac containing methylol groups by the acid-catalyzed addition-condensation of 2,2-(4-methoxyphenyl)propane and formaldehyde; this novolac acts as a novel reactive polymer. Furthermore, bisphenol A, which is often used as a raw material for polycarbonates, could be expected to show thermostability and processability after polymerization with aldehydes. In order to evaluate the performance of a novolac as a reactive polymer, curing reaction of the obtained novolac was carried out using a lowmolecular-weight phenolic resin; further, the thermal stability of the product was evaluated by thermogravimetric analysis (TGA).

\section{EXPERIMENTAL PROCEDURE}

\section{Instruments}

The Fourier transform infrared (FT-IR) spectra were recorded by using a JASCO FT-IR 460 plus spectrometer (JASCO, Tokyo, Japan). All the ${ }^{1} \mathrm{H}$ nuclear magnetic resonance (NMR) and ${ }^{13} \mathrm{C}$ NMR spectra were obtained in $\mathrm{CDCl}_{3}$ and recorded by using a $400 \mathrm{MHz}$ JEOL LNM-EX400 (JEOL, Tokyo, Japan) with 
tetramemthylsilane as the internal standard. Gel permeation chromatography was performed either by using a JASCO UV-2075 detector and a JASCO RI2031 detector (TOSOH TSKgel $\mathrm{G}^{2} 000 \mathrm{H}_{\mathrm{XL}}$ or TSKgel $\mathrm{G} 4000 \mathrm{H}_{\mathrm{XL}}$ column), using tetrahydrofuran (THF) as the eluent after calibration with polystyrene standards. The cure reaction was carried out on the ASH APS-300 hot plate (Asahi Keiki Co. Ltd., Tokyo, Japan). TGA was performed using an SII TG/DTA 6200 (Seiko Instruments Inc., Chiba, Japan) with a heating rate of $10^{\circ} \mathrm{C} \mathrm{min}^{-1}$ under a nitrogen atmosphere.

\section{Materials}

Unless otherwise noted, all reagents and chemicals were purchased from Nakarai Tasque Inc. (Kyoto, Japan), and used without further purification. 2,2-Bis(4-hydroxyphenyl)propane (bisphenol A) was obtained from TCI (Tokyo, Japan). 2,2-Bis(4-methoxyphenyl)propane (1) was prepared by Williamson ether synthesis. ${ }^{34}$ The phenolic resin with a low-molecular weight (4) was prepared according to the previous report. ${ }^{12-17}$

Addition-condensation of 2,2-bis(4-methoxyphenyl)propane (1) with formaldehyde. To a mixture of $1(1.28 \mathrm{~g}, 5 \mathrm{mmol})$ and paraformaldehyde $(0.30 \mathrm{~g}$, $10 \mathrm{mmol}$ as a formaldehyde unit) were added acetic acid $(\mathrm{AcOH}, 2 \mathrm{ml})$ and chloroform $\left(\mathrm{CHCl}_{3}, 3 \mathrm{ml}\right)$. After a few minutes of stirring, concentrated $\mathrm{H}_{2} \mathrm{SO}_{4}$ was slowly added to the reaction mixture at $0^{\circ} \mathrm{C}$, and the mixture was stirred for $10 \mathrm{~min}$ keeping the reaction temperature at $0^{\circ} \mathrm{C}$, and then continuously stirred at $50^{\circ} \mathrm{C}$ for $1.5 \mathrm{~h}$. After cooling it to ambient temperature, it was poured into methanol $(100 \mathrm{ml})$ to gain the crude product. The desired product (2) was obtained by reprecipitation with $\mathrm{THF} / \mathrm{CHCl}_{3} /$ methanol as a purplish red powder in $42 \%$ yield after drying under the reduced pressure.

${ }^{1} \mathrm{H}$ NMR $\left(400 \mathrm{MHz}, \mathrm{CDCl}_{3}, \delta\right.$ (p.p.m.)): 7.18-6.78 (aromatic $\mathrm{H}$ at $m$-position with regard to a methoxy position), 6.78-6.07 (aromatic $\mathrm{H}$ at $o$-position with regard to a methoxy position), 5.22-4.95 ( $\left.\mathrm{Ar}-\mathrm{CH}_{2}-\mathrm{OAc}\right), 4.10$ $3.66\left(\mathrm{Ar}-\mathrm{CH}_{2}-\mathrm{Ar}\right), 3.66-3.17\left(\mathrm{Ar}-\mathrm{OCH}_{3}\right), 2.18-1.92\left(\mathrm{Ar}-\mathrm{CH}_{2}-\mathrm{O}-\mathrm{C}(=\mathrm{O})-\right.$ $\left.\mathrm{CH}_{3}\right), 1.55-1.12\left(\mathrm{Ar}-\mathrm{C}\left(\mathrm{CH}_{3}\right)_{2}-\mathrm{Ar}\right) ;{ }^{13} \mathrm{C} \mathrm{NMR}\left(100 \mathrm{MHz}, \mathrm{CDCl}_{3}, \delta\right.$ (p.p.m.)): 171.2-170.6 $\left(\mathrm{Ar}-\mathrm{CH}_{2}-\mathrm{O}-\mathrm{C}(=\mathrm{O})-\mathrm{CH}_{3}\right), 157.4-150.4$ (aromatic $\left.\mathrm{C}-\mathrm{OCH}_{3}\right)$, 147.2-144.5 (aromatic $\mathrm{C}-\mathrm{C}\left(\mathrm{CH}_{3}\right)_{2}-\mathrm{Ar}$ ), 143.6-141.4 (aromatic $\mathrm{C}-\mathrm{CH}_{2}-\mathrm{Ar}$ ), 133.8-123.7 (non-substituted aromatic $C$ in the meta-position to methoxy carbon), 113.4-108.6 (non-substituted aromatic $C$ in the ortho-position to methoxy carbon), 62.7-60.1 ( $\left.\mathrm{Ar}-\mathrm{CH}_{2}-\mathrm{OAc}\right), 55.9-54.6\left(\mathrm{Ar}-\mathrm{OCH}_{3}\right), 42.3-40.9$ $\left(\mathrm{Ar}-\mathrm{C}\left(\mathrm{CH}_{3}\right)_{2}-\mathrm{Ar}\right), 32.3-30.5 \quad\left(\mathrm{Ar}-\mathrm{C}\left(\mathrm{CH}_{3}\right)_{2}-\mathrm{Ar}\right), 30.5-29.1 \quad\left(\mathrm{Ar}-\mathrm{CH}_{2}-\mathrm{Ar}\right)$, 21.4-20.7 $\left(\mathrm{Ar}-\mathrm{CH}_{2}-\mathrm{O}-\mathrm{C}(=\mathrm{O})-\mathrm{CH}_{3}\right)$; FT-IR $\left(\mathrm{KBr}, \mathrm{cm}^{-1}\right)$ : 3054 (aromatic C-H stretch), 2967 (aliphatic C-H stretch), 1744 (C=O stretch in an acetoxymethyl moiety), 1609 (aromatic $\mathrm{C}-\mathrm{C}$ stretch), $1260\left(\mathrm{Ar}-\mathrm{O}-\mathrm{CH}_{3}\right)$.
Hydrolysis of ester groups of 2. A volume of $1 \mathrm{moll}^{-1} \mathrm{KOH}$ aqueous $(2.0 \mathrm{ml})$ was added to a solution of $2(0.28 \mathrm{~g})$ in THF $(3 \mathrm{ml})$, and the mixture was stirred at ambient temperature for $72 \mathrm{~h}$. The mixture was poured into methanol $(100 \mathrm{ml})$ to obtain the desired polymer (3).

${ }^{1} \mathrm{H}$ NMR ( $400 \mathrm{MHz}, \mathrm{CDCl}_{3}, \delta$ (p.p.m.)): 7.16-6.78, 6.78-6.36 (aromatic $H$ ), 4.67-4.46 ( $\left.\mathrm{Ar}-\mathrm{CH}_{2}-\mathrm{OH}\right), 4.09-3.81\left(\mathrm{Ar}-\mathrm{CH}_{2}-\mathrm{Ar}\right), 3.81-3.13\left(\mathrm{Ar}-\mathrm{OCH}_{3}\right)$, 1.53-1.14 ( $\left.\mathrm{Ar}-\mathrm{C}\left(\mathrm{CH}_{3}\right)_{2}-\mathrm{Ar}\right)$; FT-IR $\left(\mathrm{KBr}, \mathrm{cm}^{-1}\right): 3521(\mathrm{O}-\mathrm{H}$ stretch), 3046 (aromatic C-H stretch), 2974 (aliphatic C-H stretch), 1609 (aromatic C-C stretch), $1265\left(\mathrm{Ar}-\mathrm{O}-\mathrm{CH}_{3}\right)$.

Cure reaction between 3 and 4 . The typical procedure for the cure reaction of $\mathbf{3}$ and $\mathbf{4}$ is as follows: $\mathbf{3}$ and $\mathbf{4}$ were dissolved in THF, and the solution was stirred for $1 \mathrm{~h}$. The mixture was heated at $130^{\circ} \mathrm{C}$ for several hours to vaporize solvent and water, and to carry out the cure reaction. After the reaction, the soluble part in THF was removed; as a result, the desired product (5) was obtained.

FT-IR $\left(\mathrm{KBr}, \mathrm{cm}^{-1}\right)$ : 3424 (O-H stretch), 3051 (aromatic C-H stretch), 2973 (aliphatic C-H stretch), 1609 (aromatic C-C stretch), $1254\left(\mathrm{Ar}-\mathrm{O}-\mathrm{CH}_{3}\right)$.

Cure reaction between 4 and HMTA. The phenolic resin with a low-molecular weight (4) $(1.0 \mathrm{~g})$ and HMTA $(0.1 \mathrm{~g})$ were added in a $50 \mathrm{ml}$ vial. The mixture was heated at $140^{\circ} \mathrm{C}$ for a few minutes to give the organo-insoluble resin (6).

FT-IR $\left(\mathrm{KBr}, \mathrm{cm}^{-1}\right)$ : 3305 (O-H stretch), 3050 (aromatic C-H stretch), 2982 (aliphatic C-H stretch), 1613 (aromatic C-C stretch), $1243\left(\mathrm{Ar}-\mathrm{O}-\mathrm{CH}_{3}\right)$.

\section{RESULTS AND DISCUSSION}

Addition-condensation of 2,2-bis(4-methoxyphenyl)propane (1) with formaldehyde

The addition-condensation of $\mathbf{1}$ with formaldehyde was carried out to obtain the product (2) in $42 \%$ yield (Scheme 1). The number-average molecular weight $\left(M_{\mathrm{n}}\right)$ and the polydispersity index $\left(M_{\mathrm{w}} / M_{\mathrm{n}}\right)$ of 2 were found to be 8400 and 4.3, respectively (gel permeation chromatography, eluent: THF, polystyrene standards). The structure of 2 was confirmed by FT-IR, ${ }^{1} \mathrm{H}$ NMR and ${ }^{13} \mathrm{C}$ NMR spectra. The FT-IR spectrum of $\mathbf{2}$ showed the peaks attributed to the benzene ring $\left(3054,1609 \mathrm{~cm}^{-1}\right)$, a methylene unit $\left(2967 \mathrm{~cm}^{-1}\right)$, a carbonyl group of an ester moiety $\left(1744 \mathrm{~cm}^{-1}\right)$ and a methoxy group $\left(1260 \mathrm{~cm}^{-1}\right)$ (Figure 1). From the ${ }^{1} \mathrm{H}$ NMR spectrum, the presence of aromatic and methylene bridge protons in 2 was confirmed by the peaks observed at 7.16-6.07 and 4.10-3.66, respectively; furthermore, the presence of acetoxymethyl, methoxy and acetyl protons was also verified from the peaks observed at 5.22-4.95, $3.66-3.17$ and $2.18-1.92$, respectively (Figure 2 ). The ${ }^{13} \mathrm{C}$ NMR spectrum of

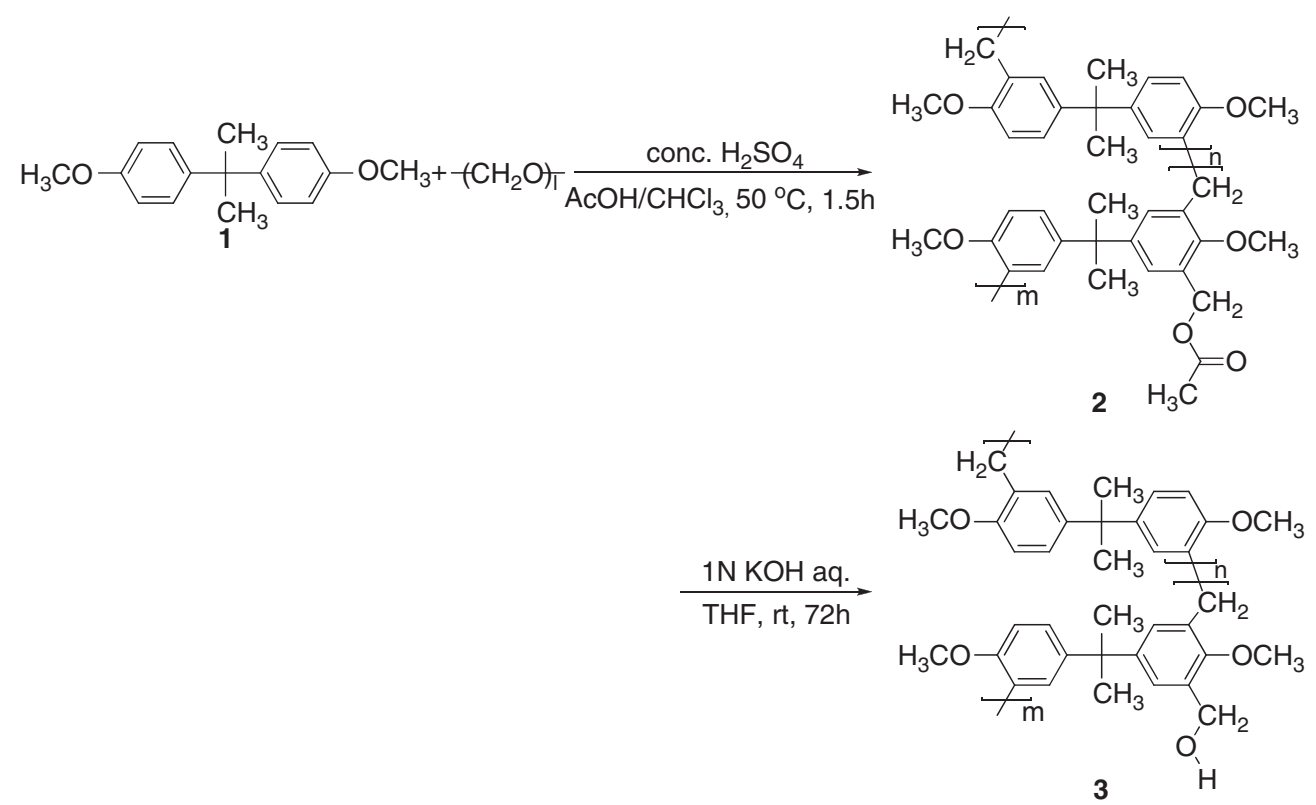

Scheme 1 Addition-condensation of 2,2-bis(4-methoxyphenyl)propane (1) with formaldehyde. 


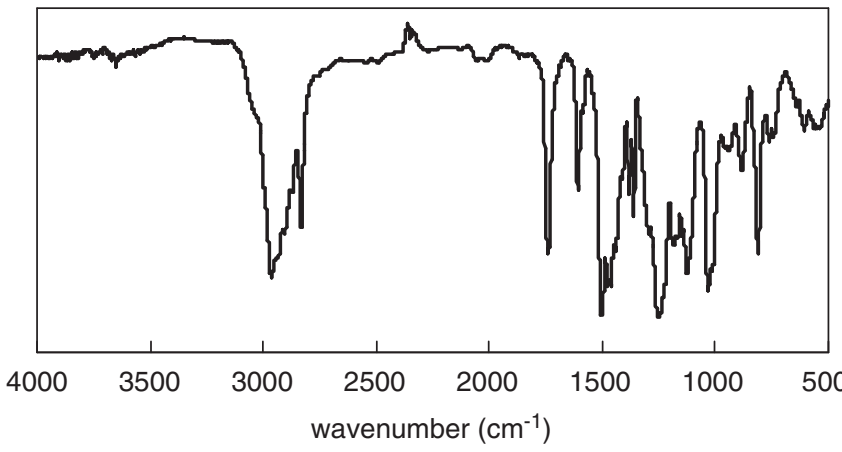

Figure 1 Fourier transform infrared spectrum of 2.
2 revealed the presence of methylene units (30.5-29.1 p.p.m.), substituted aromatic carbons attached to the methoxy groups (157.4-150.4 p.p.m.), and other carbon groups on the benzene rings (143.6-141.4, 133.8-123.7, 113.4108.6 p.p.m.); furthermore, the peaks corresponding to the acetoxymethyl moieties were observed at 171.2-170.6, 62.7-60.1 and 21.4-20.7 p.p.m., in accordance with the results of our previous report (Figure 3). ${ }^{1,33,35,36}$ These results confirmed that 2 contains arylene-methylene units, as shown in Scheme 1; moreover, some repeating units possessed acetoxymethyl moieties, which were formed by the condensation of acetic acid and methylol moieties, as described in our previous report. ${ }^{33}$

\section{Reactive novolac with a methylol group (3)}

From the above results, the bisphenol A-based novolac 2, containing an acetoxymethyl moiety in its side chains, was successfully prepared. To obtain

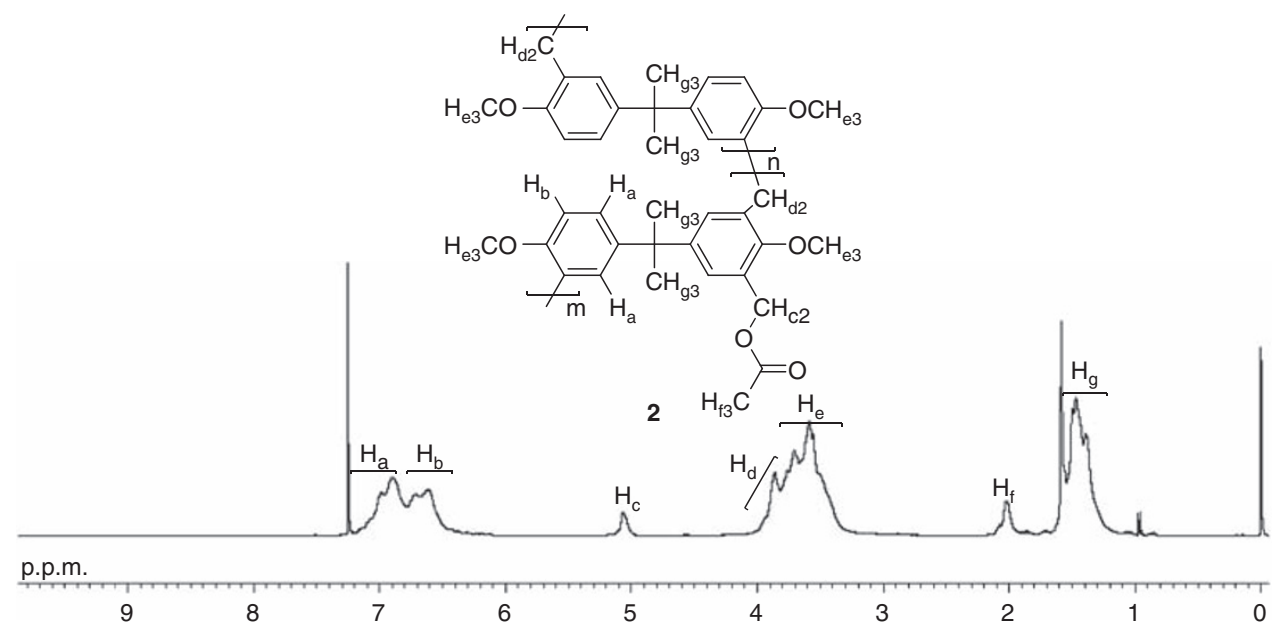

Figure $2{ }^{1} \mathrm{H}$ nuclear magnetic resonance spectrum of 2 in $\mathrm{CDCl}_{3}$.

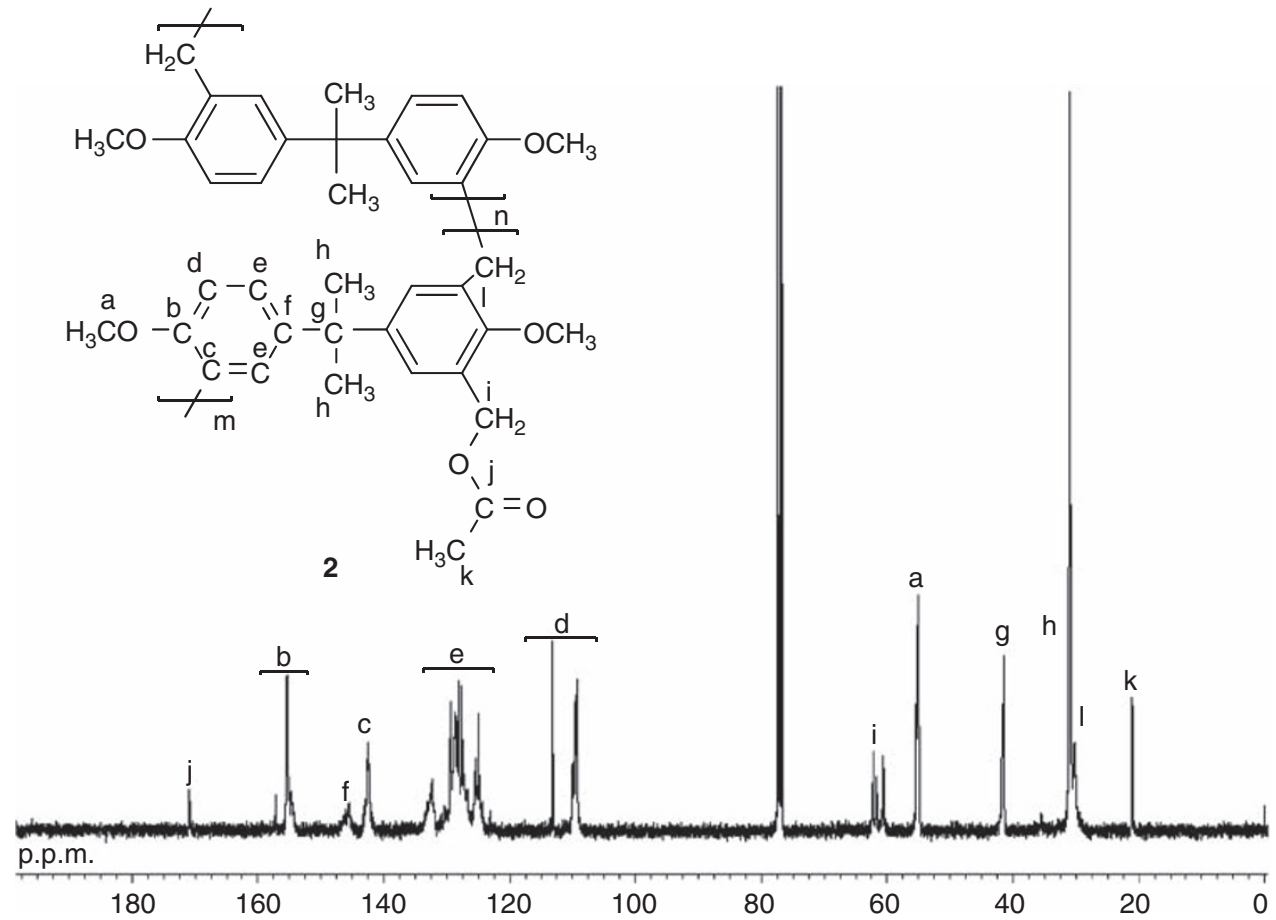

Figure $3{ }^{13} \mathrm{C}$ nuclear magnetic resonance spectrum of 2 in $\mathrm{CDCl}_{3}$. 


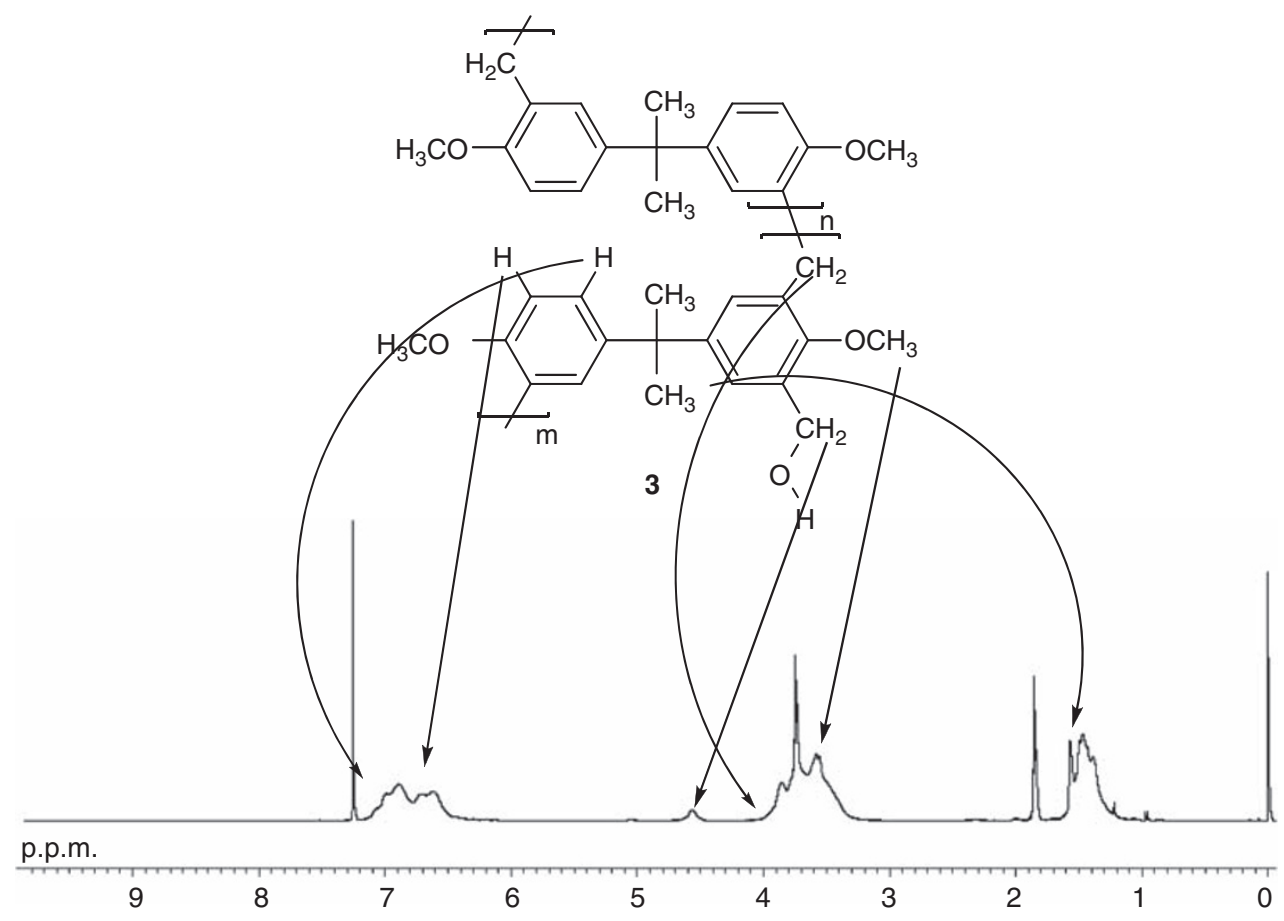

Figure $4{ }^{1} \mathrm{H}$ nuclear magnetic resonance spectrum of 3 in $\mathrm{CDCl}_{3}$.

$\mathbf{3}$ in the form of a reactive novolac with a methylol group, the hydrolysis of $\mathbf{2}$ was carried out using sodium hydroxide in the THF/water solution; this reaction afforded the completely hydrolyzed methylol group-containing novolac (3). From the ${ }^{1} \mathrm{H}$ NMR spectrum of 3, the peak attributable to the hydroxymethyl proton is observed at $4.67-4.46$ p.p.m.; however, the peak corresponding to the acetoxymethyl proton disappeared (Figure 4). In contrast, two peaks corresponding to THF proton appeared at 1.9 and 3.7 p.p.m., this indicated that THF as a reaction solvent would attach to 3 by a hydrogen bonding. Furthermore, the FT-IR spectrum of 3 did not show the peak corresponding to an ester group. These results verified that the hydrolysis reaction proceeded to completion to obtain the methylol group-containing novolac 3.

\section{Cure reaction}

In order to evaluate the reactivity of $\mathbf{3}$ and verify its role as a reactive polymer, we carried out the curing reaction between 3 and a low-molecular-weight phenolic resin (4) by annealing the two at $130{ }^{\circ} \mathrm{C}$ for a certain period; 4 was prepared according to the procedure reported previously. ${ }^{1}$ The product obtained was washed repeatedly with THF to obtain the insoluble resin (5). This insoluble product appeared to be the hardened phenolic resins of $\mathbf{4}$ cured by $\mathbf{3}$; however, there was a possibility that polymer $\mathbf{3}$ was cured itself, or $\mathbf{4}$ and $\mathbf{3}$ both cured each other. To evaluate the cross-linking reaction between $\mathbf{3}$ and $\mathbf{4}$, the TGA of 3, 4 and $\mathbf{5}$ were carried out in nitrogen atmosphere (Figure 5). The $T_{\mathrm{d} 10}$ (temperature at $10 \%$ loss in weight) values of $\mathbf{3}, \mathbf{4}$ and $\mathbf{5}$ were found to be 397,190 and $247^{\circ} \mathrm{C}$, respectively. In the weight-loss pattern of $\mathbf{5}$ in the TGA curve, the moiety derived from 4 started to show signs of breaking at around $200{ }^{\circ} \mathrm{C}$, and then showed the decomposition of a methoxy group, derived from 3 , and both the main chains at around $450{ }^{\circ} \mathrm{C}$. This behavior indicated that 5 was entirely made from 3 and $\mathbf{4}$ by the condensation between the methylol moiety of $\mathbf{3}$ and the phenolic moiety of $\mathbf{4}$. If the annealing resulted in only the self-condensation of 3 , the decomposition behavior at around $200{ }^{\circ} \mathrm{C}$ would not have been observed. In fact, resin $\mathbf{5}$ showed two kinds of decomposition behaviors in TGA and poor solubility in organic solvents; from this, it can be concluded that the curing reaction mainly proceeded by the condensation reaction between 3 and 4 . These results suggest that 3 serves as an effective reactive novolac suitable for use as a curing agent. It is expected that polymer 3

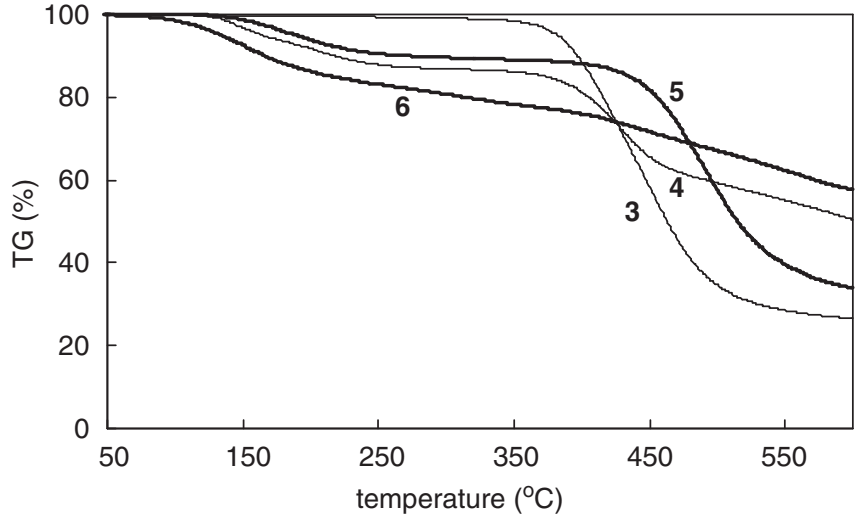

Figure 5 Thermogravimetric analyses of 3, 4, 5 and 6 in $\mathrm{N}_{2}$ flow.

can be used not only as a novel novolac-based adhesive but also as a novel reactive novolac. The $T_{\mathrm{d} 10}$ value of the conventional phenolic resin (6), which was prepared from 4 and HMTA by the method described in experimental procedure sections, was also determined by TGA and found to be $153.5^{\circ} \mathrm{C} ; \mathbf{6}$ is insoluble in organic solvents. The $T_{\mathrm{d} 10}$ value of $\mathbf{6}$ was considerably lower than those of 3-5, indicating that 6 probably included a lot of impurities trapped within its structural network; these impurities could be unreacted HMTA and various amine derivatives.

\section{CONCLUSION}

We successfully prepared a novel reactive novolac $\mathbf{3}$ having a methylol moiety. We demonstrated the effective use of $\mathbf{3}$ as a curing agent to the lower-molecular-weight phenolic resin 4 to yield the curing product 5 . $\mathbf{5}$ derived from $\mathbf{3}$ and $\mathbf{4}$ showed excellent purity and thermal stability; consequently, we achieved the HMTA-free curing reaction of 4 . Furthermore, the methylol moiety on the benzene ring can be condensed with a proton attached to the electron-rich aromatic 
ring; therefore, 3 can be applied as not only a curing agent to modify the thermal property of $\mathbf{4}$ but also an additive with curing properties to a variety of engineering plastics and common aromatic polymers in order to modify their thermal and mechanical properties. We are now starting to investigate the application of 3 for the above-mentioned purposes and in other areas.

\section{ACKNOWLEDGEMENTS}

We thank Professor Yoshiaki Nakamoto (Kanazawa University) for helpful discussion. This work was partially supported by Industrial Technology Research and Development Grant (04A23030) from NEDO of JAPAN.

1 Knop, A. \& Pilato, L. A. 'Phenolic Resins' (Springer-verlag, Berlin, 1985).

2 Crespy, D., Bozonnet, M. \& Meier, M. 100 years of bakelite, the material of a 1000 uses. Angew. Chem. Int. Ed. 47, 3322-3328 (2008).

3 Konishi, G. Precision polymerization of designed phenol: new aspects of phenolic resin chemistry. J. Syn. Org. Chem. Jpn. 66, 705-713 (2008).

4 Takeichi, T., Kawauchi, T. \& Agag, T. High performance polybenzoxazines as a novel type of phenolic resin. Polym. J. 40, 1121-1131 (2008).

5 Konishi, G. New class of aromatic polymers prepared by addition-condensation of designed phenol with formaldehyde. Kobunshi Ronbunshu 66, 331-339 (2009).

6 Matsumoto, A., Hasegawa, K., Fukuda, A. \& Otsuki, K. Study on modified phenolic resin. III. Modification with $p$-hydroxyphenylmaleimide/acrylic ester copolymer. J. Appl. Polym. Sci. 44, 1547-1556 (1992).

7 Fukuoka, T., Uyama, H. \& Kobayashi, S. Synthesis of ultrahigh molecular weight polyphenols by oxidative coupling. Macromolecules 36, 8213-8215 (2003).

8 Cui, J., Yan, Y., Liu, J. \& Wu, Q. Phenolic resin-MWNT nanocomposites prepared through an in situ polymerization method. Polym. J. 40, 1067-1073 (2008).

9 Kaith, B. S. \& Kalia, S. Grafting of flax fiber (Linum usitatissimum) with vinyl monomers for enhancement of properties of flax-phenolic composites. Polym. J. 39, 1319-1327 (2007).

10 Suzuki, K., Matsumoto, H., Minagawa, M., Kimura, M. \& Tanioka, A. Preparation of carbon fiber fabrics from phenolic resin by electrospray deposition. Polym. J. 39, 1128-1134 (2007).

11 Pan, G., Du, Z., Zhang, C., Li, C., Yang, X. \& Li, H. Effect of structure of bridging group on curing and properties of bisphenol-A based novolac epoxy resins. Polym. J. 39, 478-487 (2007).

12 Nemoto, T., Amir, I. \& Konishi, G. Synthesis and properties of a high-molecular-weight organosoluble bisphenol A novolac. Polym. J. 41, 338-342 (2009).

13 Kimura, T., Nakamoto, Y. \& Konishi, G. Preparation of organic/inorganic polymer hybrid from a new class of novolac. Polym. J. 38, 606-609 (2006).

14 Jeerupan, J., Konishi, G., Nemoto, T., Shin, D. -M. \& Nakamoto, Y. Synthesis of multifunctional poly(calix[4]resorcinarene). Polym. J. 39, 762-763 (2007).

15 Kobayashi, A. \& Konishi, G. Rapid synthesis of phenolic resins by microwave-assisted self-condensation of hydroxybenzyl alcohol derivatives. Polym. J. 40, 590-591 (2008)
16 Nemoto, T. \& Konishi, G. Synthesis and properties of new organosoluble alkoxylated naphthalene-based novolacs preparaed by addition-condensation of Mono- or di-alkoxynaphthalene with formaldehyde. Polym. J. 40, 651-656 (2008).

17 Shin, D. -M., Ozeki, N., Nakamoto, Y. \& Konishi, G. Preparation of a reactive poly(phenylenemethylene) and its application for an amphiphilic architecture. Macromol. Res. 14, 255-256 (2006).

18 Parameswaran, P. S. \& Thacil, E. T. Influence of ether linkages on the properties of resol phenolic resin. Int. J. Polym. Mater. 56, 177 (2007).

19 Byun, H. Y., Choi, M. H. \& Chung, I. J. Synthesis and characterization of resol type phenolic resin/layered silicate nanocomposites. Chem. Mater. 13, 4221-4226 (2001).

20 Kato, M., Tsukigase, A., Usuki, A., Shimo, T. \& Yazawa, H. Preparation and thermal properties of resole-type phenol resin-clay nanocomposites. J. Appl. Polym. Sci. 99, 3236-3240 (2006).

21 Kaynak, C. \& Tasan, C. C. Effects of production parameters on the structure of resol type phenolic resin/layered silicate nanocomposites. Eur. Polym. J. 42, 1908-1921 (2006).

22 Ghosh, N. N., Kiskan, B. \& Yagci, Y. Polybenzoxazines-new high performance thermosetting resins: synthesis and properties. Prog. Polym. Sci. 32, 1344-1391 (2007).

23 Fréchet, J. M. J., Darling, G. D., Itsuno, S., Lu, P. Z., de Meftahi, M. V. \& Rolls, W. A. Reactive polymers: design considerations, novel preparations and selected applications in organic chemistry. Pure Appl. Chem. 60, 353-364 (1988).

24 Ritter, H. \& Sperber, R. Diels-Alder reactions in polymer chemistry: synthesis of pyridoxine on a polymeric backbone. Macromolecules 27, 5919-5920 (1994).

25 Nishikubo, T., Kudo, H. \& Nomura, H. A novel thermal curing reaction of oxetane resin with active diester. Polym. J. 40, 310-316 (2008).

26 Mizoguchi, K. \& Ueda, M. Direct patterning of poly(ether ether sulfone) using a cross-linker and a photoacid generator. Polym. J. 40, 645-650 (2008).

27 Scott, T. F., Schneider, A. D., Cook, W. D. \& Bowman, C. N. Photoinduced plasticity in cross-linked polymers. Science 308, 1615-1617 (2005).

28 Tasdelen, M. A., Kumbaraci, V., Talinli, N. \& Yagci, Y. Photoinduced cross-linking polymerization of monofunctional vinyl monomer without conventional photoinitiator and cross-linker. Macromolecules 40, 4406-4408 (2007).

29 Matsumi, N. \& Chujo, Y. $\pi$-Conjugated organoboron polymers via the vacant $p$-orbital of the boron atom. Polym. J. 40, 77-89 (2008).

30 Sugawara, S., Tomoi, M. \& Oyama, T. Photosensitive polyesterimides based on reaction development patterning. Polym. J. 39, 129-137 (2007)

31 Nemoto, T., Amir, I. \& Konishi, G. Synthesis of a formyl group-containing reactive novolac. Polym. J. 41, 389-394 (2009).

32 Nemoto, T., Amir, I. \& Konishi, G. Synthesis of alkoxylated phenolic resins containing an acetyl group and their functionalization by Grignard reaction. Polym. J. 41, 395-401 (2009).

33 Ninagawa, A., Ijichi, I. \& Imoto, M. Formaldehyde resins. 92. Molecular weight distribution of diphenyl ether-formaldehyde resin and its structure. Makromol. Chem. 107, 196-203 (1967)

34 Feuer, H. \& Hooz, J. 'The Chemistry of Functional Groups' (ed. Patai, S.) 445 (John Wiley \& Sons, New York, USA, 1967).

35 Nemoto, T., Ueno, T., Nishi, M., Shin, D. -M., Nakamoto, Y. \& Konishi, G. Synthesis and properties of organosoluble poly(phenylenemethylene)s from substituted benzenes or naphthalenes. Polym. J. 38, 1278-1282 (2006).

36 Nemoto, T., Konishi, G., Arai, T. \& Takata, T. Synthesis and properties of fluorinecontaining Poly(arylenemethylene)s as new heat resistant denatured phenolic resins. Polym. J. 40, 622-628 (2008). 